Check for updates

Cite this: RSC Adv., 2019, 9, 13173

\title{
Synthesis and characterization of low density porous nickel zinc ferrites
}

\author{
Qiushan Yu, ab Yuchang Su, (D) *a Rabigul Tursun ${ }^{\mathrm{a}}$ and Jing Zhang ${ }^{\mathrm{a}}$
}

$\mathrm{Ni}-\mathrm{Zn}$ ferrite has important applications in the field of soft magnetic materials due to its excellent magnetic properties, but its high bulk density hinders its promotion. Herein, an oxalate precursor was prepared by a coprecipitation method with metal sulfate and oxalic acid as raw materials. The low density porous $\mathrm{Ni}-\mathrm{Zn}$ ferrite powder was prepared by thermal decomposition in an aerobic environment with the oxalate precursor. The microstructure, morphology, and dielectric and magnetic properties of $\mathrm{Ni}-\mathrm{Zn}$ ferrite were studied by thermogravimetric and differential scanning calorimetry, X-ray powder diffraction, X-ray photoelectron spectroscopy, Fourier transform-infrared spectroscopy, scanning electron microscopy, transmission electron microscopy, tap density testing for powder, vibrating sample magnetometry, specific surface and aperture analysis and vector network analysis. The results showed that the purity, morphology, grain size and saturation magnetization of $\mathrm{Ni}-\mathrm{Zn}$ ferrite were controlled by many factors such as synthetic temperature, retaining time and environmental conditions. Under an oxygen atmosphere, pure $\mathrm{Ni}-\mathrm{Zn}$ ferrite can be prepared from an oxalate precursor by a thermal process. The ferrite has a wood-splitting appearance and a multi-layered internal cavity structure, and the bulk density is only 1/3 of the general ferrite. It has good soft magnetic and microwave absorbing properties, which makes it a potential excellent material for microwave absorbers.

Received 11th February 2019

Accepted 24th April 2019

DOI: 10.1039/c9ra01076a

rsc.li/rsc-advances the bulk density and achieve a good performance in wave absorption. ${ }^{23}$ The nanoscale ferrite powder with a bulk density of only 4.03-4.32 $\mathrm{g} \mathrm{cm}^{-3}$ can be produced using hydrothermal template method with sulphate of nickel, zinc and iron as raw materials, triethylamine and polyethylene glycol as template. ${ }^{24}$ The diatomite/Ni-Zn ferrite composite was prepared by the solgel method, the density was reduced to $3.2-3.8 \mathrm{~g} \mathrm{~cm}^{-3}$, and the dielectric and magnetic losses were within the 1-1000 $\mathrm{MHz}$ frequency band. ${ }^{25}$ However, in view of the existing preparation methods, the hollow template is still easy to break, the process is complex, and the cost of preparation and the density of the products is still high, so they need to be further improved.

In order to solve the shortcomings of the existing technologies, a method of preparing oxalic acid compound salt precursor by coprecipitation and roasting precursors in air to obtain Ni-Zn ferrite is provided. This method has the advantages of lower density, simpler process, lower preparation cost and better wave absorbing property.

\section{Experimental details}

\subsection{Preparation of materials}

$\mathrm{FeSO}_{4} \cdot 7 \mathrm{H}_{2} \mathrm{O}, \mathrm{ZnSO}_{4} \cdot 7 \mathrm{H}_{2} \mathrm{O}, \mathrm{NiSO}_{4} \cdot 6 \mathrm{H}_{2} \mathrm{O}$ and $\mathrm{H}_{2} \mathrm{C}_{2} \mathrm{O}_{4} \cdot 2 \mathrm{H}_{2} \mathrm{O}$ were used as synthetic raw materials. The $\mathrm{pH}$ value was adjusted using dilute $\mathrm{NH}_{3} \cdot \mathrm{H}_{2} \mathrm{O}$, while hexadecyl trimethyl ammonium bromide (CTAB) was used as a dispersant. The NZFO precursor was synthesized by coprecipitation method and NZFO powder was prepared by thermal decomposition in oxygen atmosphere. All
${ }^{a}$ School of Materials Science and Engineering, Central South University, Changsha, 410083, China. E-mail: emlink@csu.edu.cn; Fax: +8673188830785

${ }^{b}$ School of Physics and Optoelectronic Engineering, Yangtze University, Jingzhou, 430023, China 
the reagents used are commercially available and were analytical grade. Deionized water was used without further purification.

In a typical preparation, $0.055 \mathrm{~mol} \mathrm{NiSO}_{4} \cdot 6 \mathrm{H}_{2} \mathrm{O}, 0.045 \mathrm{~mol}$ $\mathrm{ZnSO}_{4} \cdot 7 \mathrm{H}_{2} \mathrm{O}$, and $0.20 \mathrm{~mol} \mathrm{FeSO}_{4} \cdot 7 \mathrm{H}_{2} \mathrm{O}$ were dissolved in $200 \mathrm{~mL}$ deionized water and stirred until completely dissolved. Next, $0.5 \mathrm{~g}$ CTAB and $0.32 \mathrm{~mol}_{2} \mathrm{C}_{2} \mathrm{O}_{4} \cdot 2 \mathrm{H}_{2} \mathrm{O}$ were dissolved in $500 \mathrm{~mL}$ deionized water, and a diluted $\mathrm{NH}_{3} \cdot \mathrm{H}_{2} \mathrm{O}$ was added with magnetic stirring to adjust the $\mathrm{pH}$ value. Under continuous magnetic stirring at $600 \mathrm{rpm}$, the oxalic acid solution was heated to a preset temperature of $80{ }^{\circ} \mathrm{C}$ and kept at a constant temperature, then the mixed sulfate solution was pumped into the solution at a rate of $15 \mathrm{~mL} \min ^{-1}$ using a peristaltic pump, which resulted in yellowish turbidity. The solution was held at this temperature for $2 \mathrm{~h}$, then cooled to room temperature naturally and filtered. The filter residue was cleaned with deionized water and anhydrous ethanol rinse three times, dried for $24 \mathrm{~h}$ at $60{ }^{\circ} \mathrm{C}$ to obtain the oxalate precursor. The precursor was then heated to $450{ }^{\circ} \mathrm{C}$ at a rate of $2{ }^{\circ} \mathrm{C} \mathrm{min}^{-1}$, and kept at $450{ }^{\circ} \mathrm{C}$ for $30 \mathrm{~min}$, and then heated to $500-800{ }^{\circ} \mathrm{C}$ at a rate of $5{ }^{\circ} \mathrm{C} \mathrm{min}{ }^{-1}$ and kept for $2 \mathrm{~h}$ for heat preservation, and then naturally cooled with the furnace to obtain the final nickel zinc ferrite powder.

\subsection{Characterization and testing of materials}

To test and characterize the properties and structures of the samples, thermogravimetric and differential scanning calorimetry (TG-DSC) analyses were carried out using a simultaneous thermal analyzer (STA449C, NETZSCH) from $25{ }^{\circ} \mathrm{C}$ to $1000{ }^{\circ} \mathrm{C}$ at a heating rate of $10^{\circ} \mathrm{C} \mathrm{min}^{-1}$. The crystalline phase of the powders was characterized using X-ray diffraction (XRD) at room temperature with a Rigaku D/Max 2500 powder diffractometer with $\mathrm{Cu} \mathrm{K}_{\alpha}$ radiation $(\lambda=1.5406 \AA)$ at a scanning rate of $8^{\circ} \mathrm{min}^{-1}$ in the $2 \theta$ range of $10-80^{\circ}$. Sample structure bonding was characterized by Fourier-transform infrared (FTIR) spectroscopy (Nicolet Nexus) over a range of $400-2000 \mathrm{~cm}^{-1}$ and the magnetic properties of the pure NZFO samples were characterized using a vibrating sample magnetometer (VSM, Lake Shore 7410) within $1 \mathrm{~T}$ magnet at room temperature. Characterization and determination of the valence state of iron elements obtained by XPS(Escalab 250Xi). Scanning electron microscopy (SEM, FEI SIRION 200 and Nano SEM 450) and Transmission electron microscope (TEM, FEI Tecnai G2 F20) was used to assess the micromorphology of the NZFO powders and vibration density tester (VDT, WuLing TW-01) was used to obtain the density of powders. Then, surface area and porosity analyzer (Micromeritics, ASAP2460) was used to obtain the adsorption-desorption curve and mesoporous distribution curve. The dielectric and magnetic losses of the sample were analyzed by AV3672B-S vector network analyzer.

\section{Results and discussion}

\subsection{Thermal analysis}

The prepared nickel-zinc-iron oxalate precursors were analyzed by TG-DSC in argon and air respectively. The obtained curves are shown in Fig. 1.
In argon, the first endothermic peak appeared near $203.2{ }^{\circ} \mathrm{C}$ and about $19.4 \%$ of the mass was lost. Based on the analysis of the existing literature and infrared spectrum, ${ }^{26}$ it is believed the crystalline water was lost after the molecules were heated (Formula (1), M represents a transition metal element), where the loss rate of $19.4 \%$ is very close to the theoretical value of $19.7 \%$. The second endothermic peak appeared near $392.2^{\circ} \mathrm{C}$ and the mass decreased by about $41.2 \%$, which is conjectured to be the theoretical mass loss of more than $39.6 \%$ during decomposition of $\mathrm{Ni}-\mathrm{Zn}$ ferrioxalate precursor into metal oxide, carbon monoxide, carbon dioxide (Formula (2)) and reduction of some metal oxides into metal monoxide or intermetallic compounds (Formula (3)). In air, the first heat absorption peak appeared near $202.4{ }^{\circ} \mathrm{C}$ and the loss of crystal water was about 18.6\% (Formula (4)). The exothermic peak was near $347.2{ }^{\circ} \mathrm{C}$, which is when $\mathrm{CO}$ and $\mathrm{CO}_{2}$ gases were released from the oxalate and $\mathrm{CO}$ was quickly oxidized by $\mathrm{O}_{2}$ in the surrounding air and heat was released (Formula (5)). The mass reduction was about $32.8 \%$, which is less than the $39.6 \%$ weight loss in the argon environment, suggesting that the precursor was not reduced to a single or intermetallic compound with metal oxides in an aerobic environment (Formula (5)). At 520-720 ${ }^{\circ} \mathrm{C}$, the mass of the sample increased slowly by $1.1 \%$ and there was a slight exothermic peak near $582.6{ }^{\circ} \mathrm{C}$, which may be related to oxidation of the $\mathrm{Fe}^{2+}$ to $\mathrm{Fe}^{3+}$ in the compound (Formula (6)).

$$
\begin{gathered}
\mathrm{MC}_{2} \mathrm{O}_{4} \cdot 2 \mathrm{H}_{2} \mathrm{O} \rightarrow \mathrm{MC}_{2} \mathrm{O}_{4}+2 \mathrm{H}_{2} \mathrm{O} \uparrow-\mathrm{Q}_{\mathrm{T} 1}\left(\mathrm{Ar}, 170-220{ }^{\circ} \mathrm{C}\right)(1) \\
\mathrm{MC}_{2} \mathrm{O}_{4} \rightarrow \mathrm{MO}+\mathrm{CO} \uparrow+\mathrm{CO}_{2} \uparrow-\mathrm{Q}_{\mathrm{T} 2}\left(\mathrm{Ar}, 345-425{ }^{\circ} \mathrm{C}\right) \\
\mathrm{MO}+\mathrm{CO} \rightarrow \mathrm{M}+\mathrm{CO}_{2} \uparrow-\mathrm{Q}_{\mathrm{T} 3}\left(\mathrm{Ar}, 345-425^{\circ} \mathrm{C}\right) \\
\mathrm{MC}_{2} \mathrm{O}_{4} \cdot 2 \mathrm{H}_{2} \mathrm{O} \rightarrow \mathrm{MC}_{2} \mathrm{O}_{4}+2 \mathrm{H}_{2} \mathrm{O} \uparrow-\mathrm{Q}_{\mathrm{T} 4}\left(\mathrm{Air}, 170-220^{\circ} \mathrm{C}\right)(4) \\
2 \mathrm{MC}_{2} \mathrm{O}_{4}+\mathrm{O}_{2} \rightarrow 2 \mathrm{MO}+4 \mathrm{CO}_{2} \uparrow+\mathrm{Q}_{\mathrm{T} 5}\left(\mathrm{Air}, 345-425^{\circ} \mathrm{C}\right) \\
\mathrm{O}_{2}+\mathrm{MFeO} \rightarrow \mathrm{MFe}_{2} \mathrm{O}_{4}+\mathrm{Q}_{\mathrm{T} 6}\left(\mathrm{Air}, 520-720^{\circ} \mathrm{C}\right)
\end{gathered}
$$

According to changes in TG-DSC curve characteristics, it can be deduced that pyrolysis of the oxalate sample can be divided

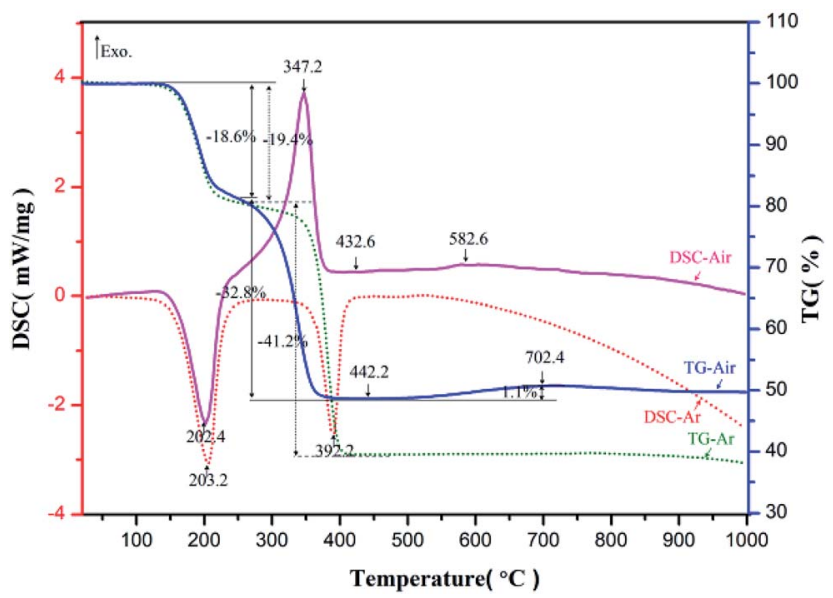

Fig. 1 TG-DSC curves of Ni-Zn ferrioxalate precursor. 
into three steps. First, the crystalline water was lost near $203^{\circ} \mathrm{C}$. Then, the oxalate decomposed into tiny grains of iron oxide, zinc oxide, and nickel oxide at $345-425{ }^{\circ} \mathrm{C}$, where they mixed uniformly and were in contact with each other and the interfacial resistance between the crystals was low. Finally, in the range of $520-720^{\circ} \mathrm{C}$, each tiny grain of solid state reaction was capable of generating NZFO at a low temperature. Analysis of samples using XRD and FT-IR spectroscopy supports these inferences.

\subsection{Structural analysis}

Fig. 2 presents the XRD spectra of oxalate precursor, $\mathrm{FeC}_{2} \mathrm{O}_{4}$ $\cdot 2 \mathrm{H}_{2} \mathrm{O}$ (JCPDS no. 23-0293), $\mathrm{ZnC}_{2} \mathrm{O}_{4} \cdot 2 \mathrm{H}_{2} \mathrm{O}$ (JCPDS no. 25-1029), and $\mathrm{NiC}_{2} \mathrm{O}_{4} \cdot 2 \mathrm{H}_{2} \mathrm{O}$ (JCPDS no. 25-0581). The latter three contain the same number of spatial groups (no. 15) in their crystal structures and belong to the monoclinic system. The Fe has an atomic radius similar to $\mathrm{Ni}$ and $\mathrm{Zn}$, while the characteristic XRD peak of the oxalate precursor was similar to the latter three compounds. However, there were no single $\mathrm{FeC}_{2} \mathrm{O}_{4} \cdot 2 \mathrm{H}_{2} \mathrm{O}$, $\mathrm{ZnC}_{2} \mathrm{O}_{4} \cdot 2 \mathrm{H}_{2} \mathrm{O}$, or $\mathrm{NiC}_{2} \mathrm{O}_{4} \cdot 2 \mathrm{H}_{2} \mathrm{O}$ peaks, combined with infrared spectroscopy, indicating the $\mathrm{Fe}^{2+}, \mathrm{Zn}^{2+}$ and $\mathrm{Ni}^{2+}$ in the oxalate precursor have been coprecipitated. The precursor was a complex, rather simple, mixture of ferrous oxalate and oxalic acid nickel or zinc oxalate.

Fig. 3 displays the XRD diffraction patterns and standard spectra of precursor samples after calcination for $2 \mathrm{~h}$ at 500$800{ }^{\circ} \mathrm{C}$. The obtained XRD diffraction patterns for each sample contain the diffraction peak of $\mathrm{Ni}_{0.5} \mathrm{Zn}_{0.5} \mathrm{Fe}_{2} \mathrm{O}_{4}$ (JCPDS file no. 08-0234) with the spinel structure: at the $2 \theta$ diffraction angles $18.3^{\circ}, 30.1^{\circ}, 35.4^{\circ}, 37.1^{\circ}, 43.0^{\circ}, 53.4^{\circ}, 56.9^{\circ}$ and $62.5^{\circ}$, there were peaks reflective of crystalline surfaces with (111), (220), (311), (222), (400), (422), (511) and (440). There were no obvious heterozygous peaks in the diffraction patterns after $2 \mathrm{~h}$ at 500$700{ }^{\circ} \mathrm{C}$ in the air, indicating that the samples had good purity. Conversely, there were still some clutter peaks after $2 \mathrm{~h}$ at $600^{\circ} \mathrm{C}$

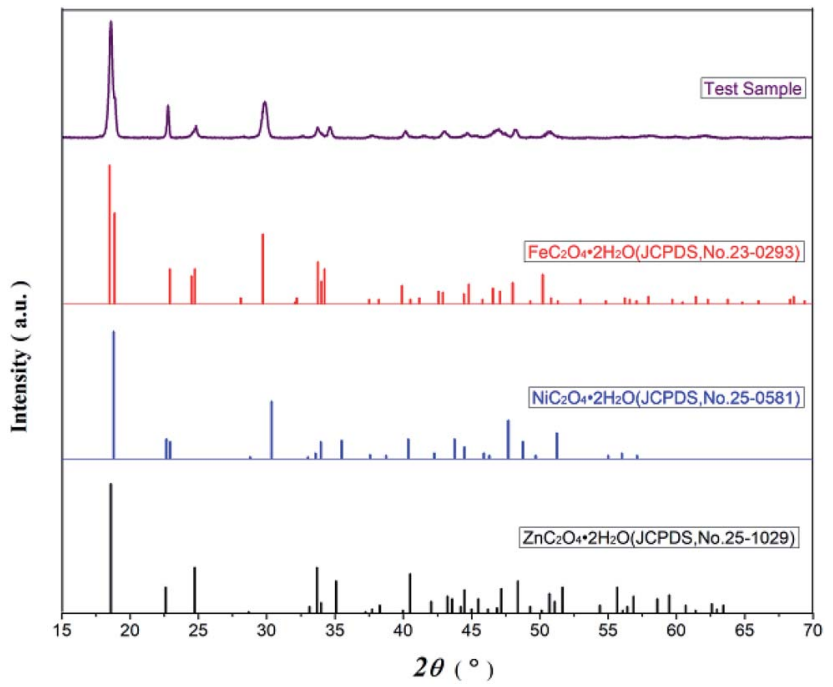

Fig. 2 The XRD patterns of $\mathrm{Ni}-\mathrm{Zn}$ ferrioxalate precursors and corresponding oxalate.

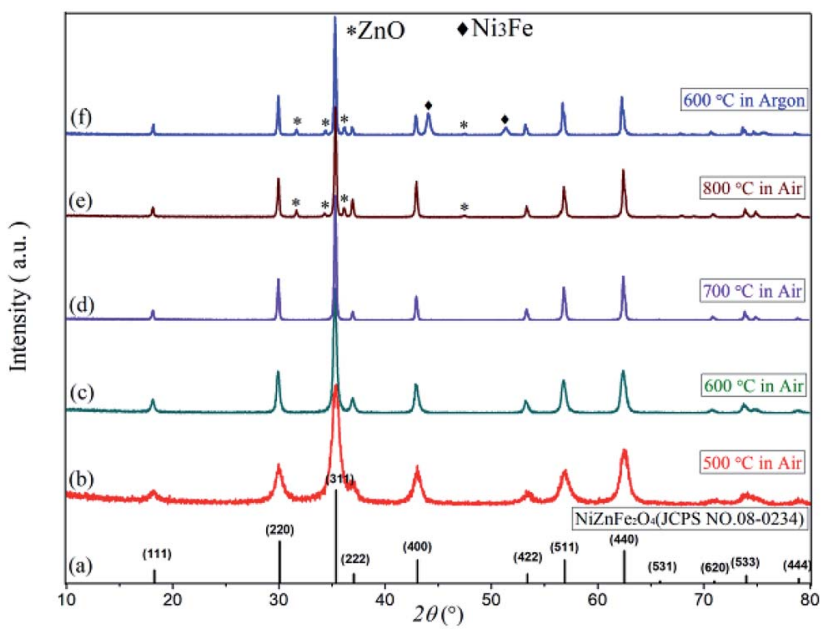

Fig. 3 The XRD patterns of (a) $\mathrm{Ni}_{0.5} \mathrm{Zn}_{0.5} \mathrm{Fe}_{2} \mathrm{O}_{4}$ standard diffraction pattern, (b)-(f) $\mathrm{Ni}_{0.55} \mathrm{Zn}_{0.45} \mathrm{Fe}_{2} \mathrm{O}_{4}$ diffraction pattern.

in argon gas. Based on these data, combined with the TG-DSC curve analysis from Fig. 1, Ni-Zn ferrites can be synthesized at $500{ }^{\circ} \mathrm{C}$. Because $\mathrm{ZnO}$ or other heterozygous phases can be found at $800{ }^{\circ} \mathrm{C}$, the pure phase can be synthesized only at 600$700{ }^{\circ} \mathrm{C}$ and an environment containing oxygen is necessary for obtaining pure NZFO.

The average sizes of the crystal grains in the samples can be calculated using Debye-Sherr's formula: ${ }^{27}$

$$
D=\frac{0.89 \lambda}{\beta \cos \theta}
$$

where $D$ is the crystal grain size, 0.89 is Sherr's constant, $\lambda=$ $1.5406 \AA$ is the wavelength of the X-ray Cu $\mathrm{K}_{\alpha}$ source, $\beta$ is the width at half-maximum of the diffraction peaks, and $\theta$ is the diffraction angle. The average crystal grain size in the samples ranged from $10.6 \pm 0.4$ to $58.6 \pm 0.9 \mathrm{~nm}$. During treatment, the crystal grew gradually as the temperature increased. In order to obtain a smaller crystal grain size, treatment has to be performed at a lower temperature.

\subsection{FT-IR analysis}

The samples of precursor and calcinator were mixed with $\mathrm{KBr}$ and pressed into tablets respectively. The infrared spectra with wavenumber of $400-2000 \mathrm{~cm}^{-1}$ were measured by FT-IR spectrometer. The curves (a) and (b) were obtained as shown in Fig. 4. The strong absorption peaks near $1360 \mathrm{~cm}^{-1}$ and $1312 \mathrm{~cm}^{-1}$ indicate that a large number of $\mathrm{OH}$ radicals existed in the curves (a), ${ }^{28}$ but disappeared in the curves (b), indicating that the $\mathrm{OH}$ radicals in the precursors were removed after calcination. In addition, the oxalate precursor lost the crystalline water; the same phenomenon also appeared in the curve (a) around $822 \mathrm{~cm}^{-1} \mathrm{C}-\mathrm{C}$ bending vibration absorption peak, ${ }^{28}$ after heat treatment disappeared in the curve (b), indicating that oxalate was removed in heat treatment, which can be verified by TG-DSC and XRD test results. There were two strong characteristic absorption peaks in the $550-670 \mathrm{~cm}^{-1}$ of the curve (a), which should be caused by the stretching vibration of 


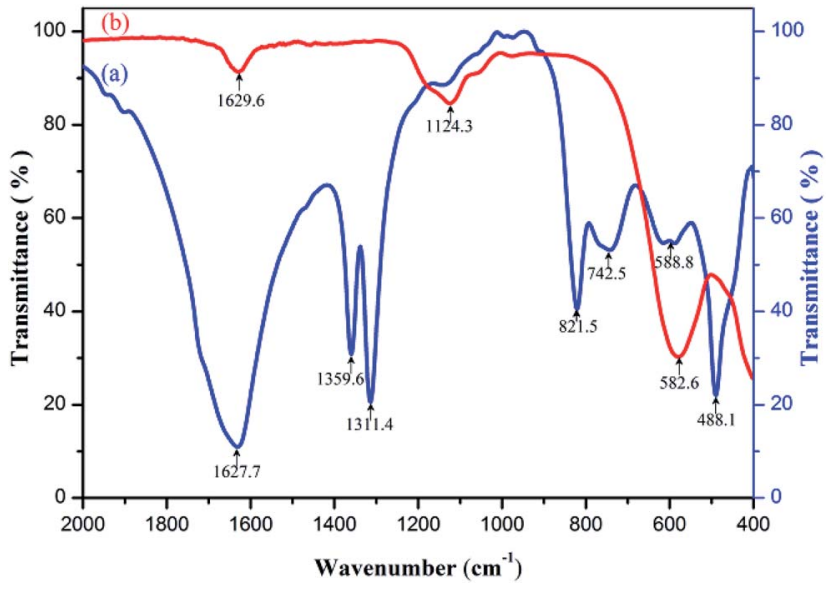

Fig. 4 Infrared spectra of (a) $\mathrm{Ni}-\mathrm{Zn}$ ferrioxalate precursor, (b) $\mathrm{Ni}_{0.55}$ $\mathrm{Zn}_{0.45} \mathrm{Fe}_{2} \mathrm{O}_{4}$ obtained by calcining the precursor at $600^{\circ} \mathrm{C}$ for $2 \mathrm{~h}$.

$\mathrm{Zn}-\mathrm{O}, \mathrm{Ni}-\mathrm{O}$ and the winding vibration of $\mathrm{Fe}-\mathrm{O}$ in the tetrahedron. ${ }^{29-33}$ After burning, the two peaks disappeared completely, and a new single absorption peak of metal oxides appeared near $583 \mathrm{~cm}^{-1}$ in the curve (b). XRD and Energy Dispersive Spectrometer (EDS) analysis showed that the two peaks were from $\mathrm{Ni}-\mathrm{Zn}$ ferrite. In addition, there were some stretching vibration absorption peaks near $1124 \mathrm{~cm}^{-1}$ and some stretching vibration absorption peaks near $488 \mathrm{~cm}^{-1}$, which may be related to the residual sulfate in the sample.

\subsection{XPS analysis}

In $\mathrm{Ni}-\mathrm{Zn}$ ferrite, the valence state of iron element can affect its ability to occupy the B site in the octahedron or the A site in the tetrahedron, which will affect the crystal structure, properties and bulk density of the ferrite. We used XPS to characterize and analyze the valence state of iron element in the compound. The XPS peaks obtained from the samples were calibrated by the C1s peak at $284.68 \mathrm{eV}$, and the Lorentz function was used to fit and analyze the peaks of the elements in the spectrum.

In the XPS band spectrum of the sample, the binding energy interval of $705.0 \mathrm{eV}$ to $730.0 \mathrm{eV}$ is one of the intervals in which the characteristic spectrum of iron element is located, ${ }^{34}$ as shown in Fig. 5. There are spin-orbital energy peaks belonging to $\mathrm{Fe} 2 \mathrm{P}_{3 / 2}$ and $\mathrm{Fe} 2 \mathrm{P}_{1 / 2}$ near the two positions of $710.4 \mathrm{eV}$ and $724.2 \mathrm{eV}$. These values of spin-orbital binding energy are slightly lower than Fe $2 \mathrm{P}_{1 / 2}(724.4 \mathrm{eV})$ and $\mathrm{Fe} 2 \mathrm{P}_{3 / 2}(711.0 \mathrm{eV})$ of $\mathrm{Fe}_{2} \mathrm{O}_{3}$, but higher than $\mathrm{Fe} 2 \mathrm{P}_{1 / 2}(722.6 \mathrm{eV})$ and $\mathrm{Fe} 2 \mathrm{P}_{3 / 2}(709.0 \mathrm{eV})$ of $\mathrm{Fe}_{2} \mathrm{SiO}_{4} \cdot{ }^{35}$ This implies that they may be composite peaks formed by $\mathrm{Fe}^{2+}$ and $\mathrm{Fe}^{3+}$ ions in the vicinity of the $\mathrm{Fe} 2 \mathrm{P}_{3 / 2}$ orbital. To this end, the Fe $2 \mathrm{P}_{3 / 2}$ peak near $710.4 \mathrm{eV}$ was fitted to the peak, while the two peaks with peak values of $711.0 \mathrm{eV}$ and $709.0 \mathrm{eV}$ were successfully separated, indicating that the speculation is correct. The compound contains both $\mathrm{Fe}^{2+}$ and $\mathrm{Fe}^{3+}$ ion.

\subsection{SEM and TEM characterization}

Fig. 6(a) and (b) shows the SEM morphology of two Ni-Zn oxalate precursors and $\mathrm{Ni}-\mathrm{Zn}$ ferrites. They are all wood-

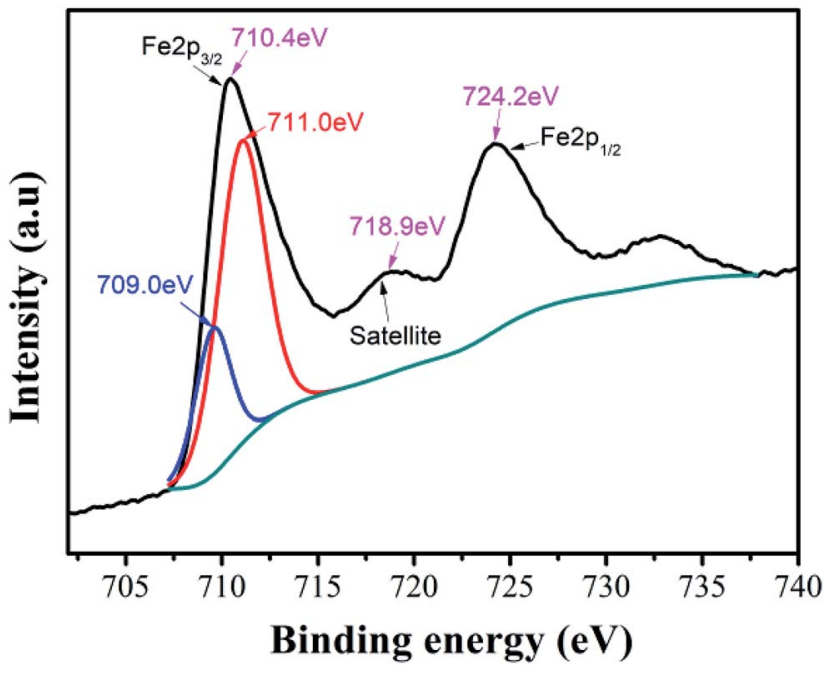

Fig. 5 Iron ion XPS spectra of $\mathrm{Ni}-\mathrm{Zn}$ ferrite.

splitting shapes, and the ratio of radial to axial increases with the decrease of temperature.

The prepared $\mathrm{Ni}-\mathrm{Zn}-\mathrm{Fe}$ oxalate compounds was a monoclinic system, where its metal cations $\left(\mathrm{M}^{2+}=\mathrm{Fe}^{2+}, \mathrm{Ni}^{2+}\right.$, and $\mathrm{Zn}^{2+}$ ) and oxalic acid radical groups formed an infinite chain, as shown in Fig. 7(a). The oxalate radical group played the role of the four-tooth ligand here. $\mathrm{M}^{2+}$ was connected to two $\mathrm{H}_{2} \mathrm{O}$, forming one deformed $\mathrm{MO}_{6}$ octahedra environment parallel to the $b$ axis and formed a regular arrangement in the layered structure. The layered structure was perpendicular to the $c$ axis, as shown in Fig. 7(b). Therefore, the oxalate compound had an anisotropic structure along the $b$ axis and the one-dimensional characteristics of the chain structure greatly influenced anisotropic growth of them. ${ }^{36}$ The oxalate complex had a similar chain structure, but these chain structures became mixed when formation is laminar, which rearranges hydrogen bonds between layers. ${ }^{2}$ When the $\mathrm{pH}$ value is low, there is a higher concentration of $\mathrm{H}^{+}$in the solution and the oxalic acid compound salt chain structure has a relatively greater role. Therefore, the growth rate was faster in this direction, leading to formation of a rod shape, and the increase of temperature helps to strengthen this advantage (Fig. 6(a)). The rapid extension and growth of the oxalate molecular chain hinders the close bonding between the layers to some extent, so that the precursors generate more voids after the loss of organic matter during the roasting process, and become relatively more delicate.

Fig. 6(d) is a TEM photograph and a SAED (selected area electron diffraction) pattern of the sample in Fig. 6(a2). It can be seen from the figure that the sample particles are mainly spheroidal nano-grains, and there are many voids between the grains, and some grains are agglomerated. The grain size is slightly larger than the calculated value of XRD (see Table 2). The crystal faces corresponding to the electron diffraction patterns of the crystal grains are (220), (311), (400), (511), etc., which are consistent with the XRD analysis results described above. 

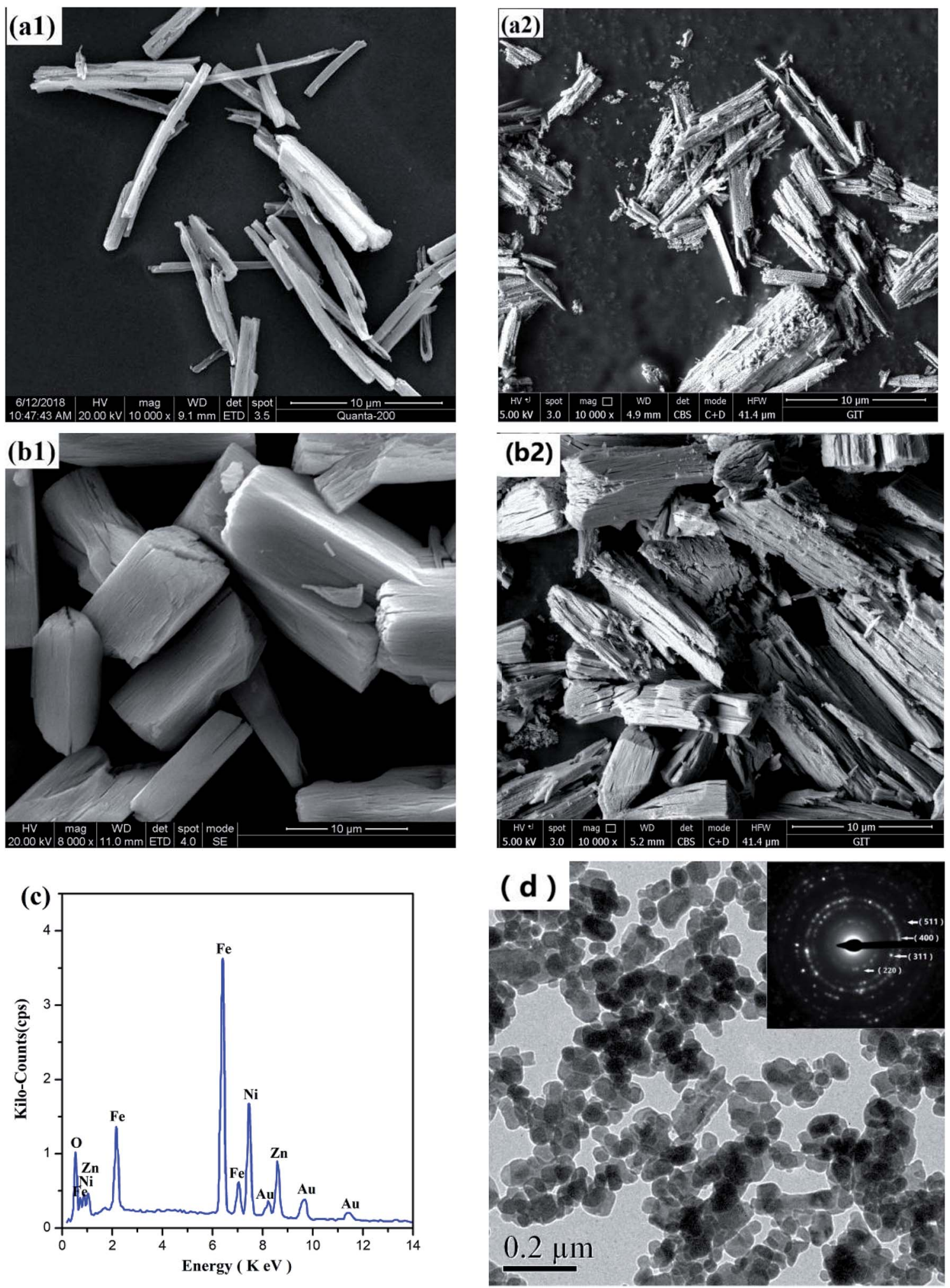

Fig. $6 \mathrm{SEM}$ images of $\mathrm{Ni}-\mathrm{Zn}$ oxalate precursor under (a1) $80^{\circ} \mathrm{C}$, (b1) $60^{\circ} \mathrm{C}$ and corresponding Ni-Zn ferrites (a2), (b2); (c) EDS diagram of NZFO in (a2); (d) TEM images and SAED of Ni-Zn ferrite.

In order to obtain a point on the surface of sample in Fig. 6(a2) and quantitatively determine the elements by EDS, the target element content (Atomic\%) of the sample determined by
ZAF modification method is $\mathrm{Fe}: \mathrm{Ni}: \mathrm{Zn} \approx 56.2: 14.4: 11.5 \approx$ $2: 0.51: 0.41$, which is close to the preset metal element ratio of $\mathrm{Ni}_{0.55} \mathrm{Zn}_{0.45} \mathrm{Fe}_{2} \mathrm{O}_{4}$ (Fig. 6(c)). ${ }^{37}$ 
(a)
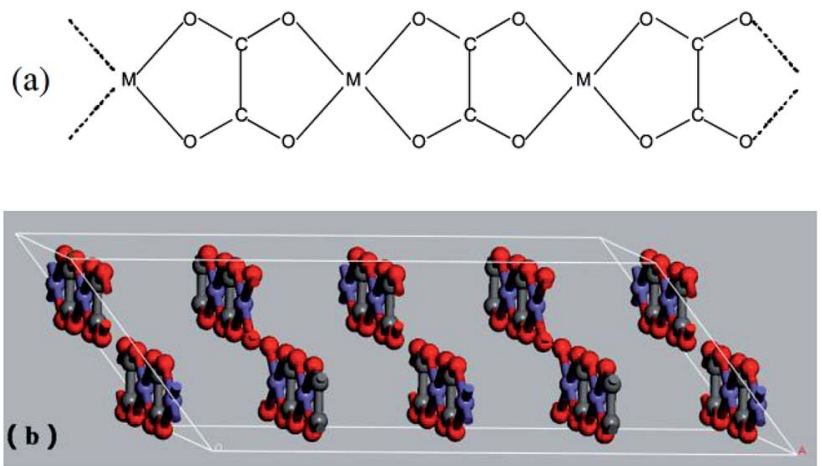

Fig. 7 (a) Schematic drawing of infinite chain arrangement present in $\mathrm{Fe}^{2+}$ oxalates of $\mathrm{MFeC}_{2} \mathrm{O}_{4} \cdot n \mathrm{H}_{2} \mathrm{O}$; (b) the layered structure of $\mathrm{MFeC}_{2} \mathrm{O}_{4} \cdot n \mathrm{H}_{2} \mathrm{O}$.

\subsection{Density measurement and pore size distribution characterization}

The porous structure of nickel-zinc ferrite helps to reduce its bulk density. There are many holes on the surface of ferrite, and there are residual holes in the cross section (Fig. 6(a2) and (b2)). Because of the porous structure of Ni-Zn ferrite, and the density of the powder measured by the tap density method is only $0.76-$ $0.78 \mathrm{~g} \mathrm{~cm}^{-3}$. It is about $1 / 3$ to general Ni-Zn ferrite at $2.3 \mathrm{~g} \mathrm{~cm}^{-3}$ (Table 1). ${ }^{24,25}$

In order to identify the nature of the pores and low bulk density formed in NZFO, the samples were vacuum treated at $150^{\circ} \mathrm{C}$ for $10 \mathrm{~h}$ to remove moisture, and then the $\mathrm{N}_{2}$ adsorptiondesorption isotherms of the samples were measured by a multipurpose adsorption instrument. The specific surface area and pore volume were calculated by Barrett-Emmett-Teller (BET) and Barrett-Joyner-Halenda (BJH) method, and the results are shown in Fig. 8(a) and (b).
The $\mathrm{N}_{2}$ adsorption-desorption isotherm curves are shown in Fig. 8(a). In the low pressure section, the adsorption amount increases gently, and the adsorption amount increases rapidly when $P / P_{0}$ is between 0.3 to 0.9 , and the adsorption curve becomes steep when $P / P_{0}$ is between 0.9 to 1.0. The curve change indicate that the sample has characteristics of a class IV curve. $^{38}$ The desorption branch is located above the adsorption branch, and both tend to be parallel in the vicinity of the saturated vapor pressure when $P / P_{0}$ is between 0.9 to 1.0 , forming a hysteresis loop with $\mathrm{H} 3$ characteristics. ${ }^{39}$ By characterizing the morphology of the sample and the $\mathrm{BJH}$ aperture algorithm using TEM and SEM, we believe that the grains in the NZFO powder are loose and accumulate into mesopores with multi-layered sheet and a pore size of 50 to $80 \mathrm{~nm}$ (Fig. 8(b)). BET surface area is $15.85 \mathrm{~m}^{2} \mathrm{~g}^{-1}$, and BJH adsorption cumulative surface area of pores between $1.70 \mathrm{~nm}$ to $300.00 \mathrm{~nm}$ width is $13.30 \mathrm{~m}^{2} \mathrm{~g}^{-1}$, while BJH Desorption cumulative surface area of pores is $13.01 \mathrm{~m}^{2} \mathrm{~g}^{-1}$. These features are formed due to the following reasons: (1) the oxalate precursor is slowly oxidized during the slow heating process, and the gas is released, which leads to the formation of a large number of pore channels; (2) the organic matter in the precursor is oxidized and disappears, volume shrinks, and numerous voids between the grains form, which makes the grains loose and contributes to the formation of pores. These pores are beneficial to the improvement of microwave absorption performance and the decrease of ferrite body density.

\subsection{Magnetic analysis}

The magnetic properties of the NZFO nanopowders were studied by VSM magnetometer. The observed hysteresis loop $(M-H)$ curve is shown in Fig. 9. The relative magnetic properties, such as saturation magnetization $\left(M_{\mathrm{s}}\right)$, coercive force $\left(H_{\mathrm{c}}\right)$, and remanent magnetization $\left(M_{\mathrm{r}}\right)$ are shown in Table 2.

Table 1 Density determination of $\mathrm{Ni}-\mathrm{Zn}$ ferrite prepared under different conditions

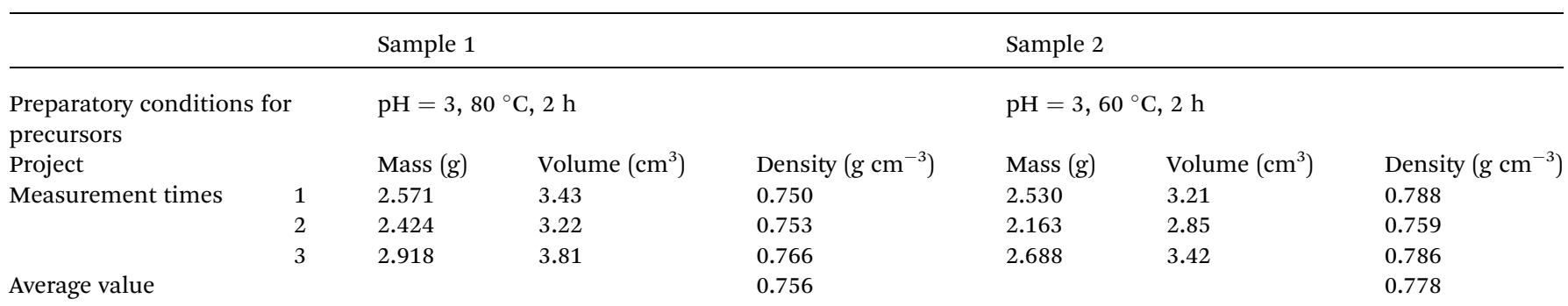

Table 2 Grain size and magnetic parameters $\left(M_{s}, M_{r}, H_{c}\right.$ and $\left.M_{r} / M_{s}\right)$ of NZFO samples at room temperatures

\begin{tabular}{|c|c|c|c|c|c|c|}
\hline Sample number & Heat preservation time & Grain size $(\mathrm{nm})$ & $M_{\mathrm{s}}\left(\mathrm{emu} \mathrm{g}^{-1}\right)$ & $M_{\mathrm{r}}\left(\mathrm{emu} \mathrm{g}^{-1}\right)$ & $H_{\mathrm{c}}$ (Gauss) & $M_{\mathrm{r}} / M_{\mathrm{s}}$ \\
\hline NZFO-500 & $2 \mathrm{~h}$ & $10.6 \pm 0.4$ & $9.564 \pm 0.06$ & $1.125 \pm 0.01$ & $83.102 \pm 0.04$ & 0.118 \\
\hline NZFO-600 & $2 \mathrm{~h}$ & $20.5 \pm 0.4$ & $\begin{array}{l}33.193 \pm 0.09 \\
36 \text { (ref. } 40 \text { ) }\end{array}$ & $1.638 \pm 0.02$ & $\begin{array}{l}35.676 \pm 0.05 \\
167 \text { (ref. } 40 \text { ) }\end{array}$ & 0.049 \\
\hline NZFO-600-1 & $3 \mathrm{~h}$ & $34.7 \pm 0.5$ & $57.946 \pm 0.07$ & $9.033 \pm 0.01$ & $83.224 \pm 0.03$ & 0.156 \\
\hline NZFO-700 & $2 \mathrm{~h}$ & $29.2 \pm 0.7$ & $43.761 \pm 0.06$ & $4.128 \pm 0.02$ & $77.426 \pm 0.03$ & 0.094 \\
\hline NZFO-800 & $2 \mathrm{~h}$ & $58.6 \pm 0.9$ & $55.934 \pm 0.09$ & $5.480 \pm 0.01$ & $84.024 \pm 0.05$ & 0.098 \\
\hline
\end{tabular}


As shown in Fig. 9 and Table 2, the NZFO samples prepared by coprecipitation displayed obvious hysteresis behavior and the $M_{\mathrm{s}}, M_{\mathrm{r}}$, and $H_{\mathrm{c}}$ of NZFO-600 were $33.2 \mathrm{emu} \mathrm{g}^{-1}, 1.64 \mathrm{emu}$ $\mathrm{g}^{-1}$, and 35.6 gauss, respectively. The soft magnetic properties were close to or superior to those prepared using the sol-gel method by J. P. Gao (600 ${ }^{\circ} \mathrm{C}$ NZFO, $M_{\mathrm{s}} 36 \mathrm{emu} \mathrm{g}^{-1}$, and $H_{\mathrm{c}} 167$ gauss). ${ }^{40}$ As the temperature increased, the $M_{\mathrm{s}}, M_{\mathrm{r}}$, and $H_{\mathrm{c}}$ of NZFO gradually increased, but the $M_{\mathrm{r}} / M_{\mathrm{s}}$ first decreased and then increased. This latter phenotype can be attributed to improvements in sample crystallinity, increases in grain size, and decreases in the number of spin suspension bonds on the surface, which lead to increases in the net spin moment and $M_{\mathrm{s}}$. When the size was larger than the critical grain size, the domain wall formed gradually and the coercive force decreased as the domain wall formed. ${ }^{\mathbf{4 1 , 4 2}}$ With the prolongation of heat preservation time, the grain size increased along with the $M_{\mathrm{s}}, M_{\mathrm{r}}, H_{\mathrm{c}}$ and $M_{\mathrm{r}} / M_{\mathrm{s}}$. An increase in the latter three parameters is not conducive to the application of soft magnetic materials. NZFO600 has the minimum remanence ratio and a narrow hysteresis loop, showing soft magnetism, a high remanence ratio, and a small coercive force can improve magnetic and electrical coupling, making it more advantageous in application in high frequency soft magnetic mediums. ${ }^{43}$

\subsection{Analysis of microwave absorbing properties}

The electromagnetic properties of the $\mathrm{Ni}-\mathrm{Zn}$ ferrite samples were tested by a vector network analyzer. The results are shown in Fig. 10(a)-(c). The dielectric properties are expressed by complex permittivity, the real part is the storage capacity of electric energy, and the imaginary part is the consumption capacity of electric energy. ${ }^{\mathbf{4 4 , 4 5}}$ Magnetic properties can be expressed as complex permeability, real part as magnetic energy storage capacity, and imaginary part as magnetic energy consumption capacity. ${ }^{2,44}$

Fig. 10(a) is a diagram of the dielectric constant of $\mathrm{Ni}-\mathrm{Zn}$ ferrites with frequency. The real part and imaginary part are about two times the real and imaginary parts of the diatomite/ $\mathrm{Ni}-\mathrm{Zn}$ ferrites prepared by sol-gel method, ${ }^{25}$ indicating that the

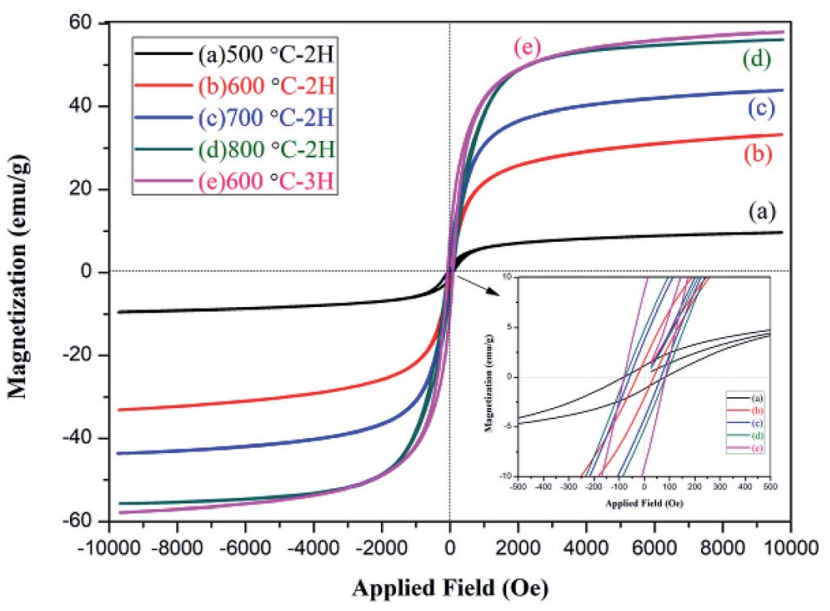

Fig. $9 \mathrm{M}-\mathrm{H}$ loops of $\mathrm{Ni}_{0.55} \mathrm{Zn}_{0.45} \mathrm{Fe}_{2} \mathrm{O}_{4}$ nanocrystalline ferrites.

samples have stronger dielectric parameters than the latter. Fig. 10(b) shows the frequency dependent permeability curve of $\mathrm{Ni}-\mathrm{Zn}$ ferrite sample. The real and imaginary values of permeability are weaker than those of diatomite/Ni-Zn ferrite (literature). Fig. 10(c) shows the reflection spectrum of the sample to 2-18 GHz microwave. When the film thickness is $5.0 \mathrm{~mm}$, the sample has an extreme value of $-34.7 \mathrm{~dB}$ nearby the $4.2 \mathrm{GHz}$, and the reflectivity of other thicknesses of films is mostly lower than $-5 \mathrm{~dB}$. The microwave absorption performance of the films is better than that of diatomite/Ni-Zn ferrite. ${ }^{25}$

The electromagnetic properties of spinel ferrite mainly depend on the distribution of metal ions in the crystal structure and the spatial structure of the grain. In spinel ferrites, oxygen ions locate in cubic dense packing, and metal ions are distributed in the oxygen ion gap, as shown in the following Formula (8):

$$
\left(\mathrm{Me}_{\delta}^{2+} \mathrm{Fe}_{1-\delta}^{3+}\right)\left[\mathrm{Me}_{1-\delta}{ }^{2+} \mathrm{Fe}_{1+\delta}{ }^{3+}\right] \mathrm{O}_{4}
$$

The ions in ( ) occupy position A (tetrahedral gap), and the ions in [ ] occupy position $\mathrm{B}$ (octahedral gap). In $\mathrm{Ni}_{0.55} \mathrm{Zn}_{0.45^{-}}$ $\mathrm{Fe}_{2} \mathrm{O}_{4}$, the order of the ability of metal ions to occupy position $\mathrm{A}$
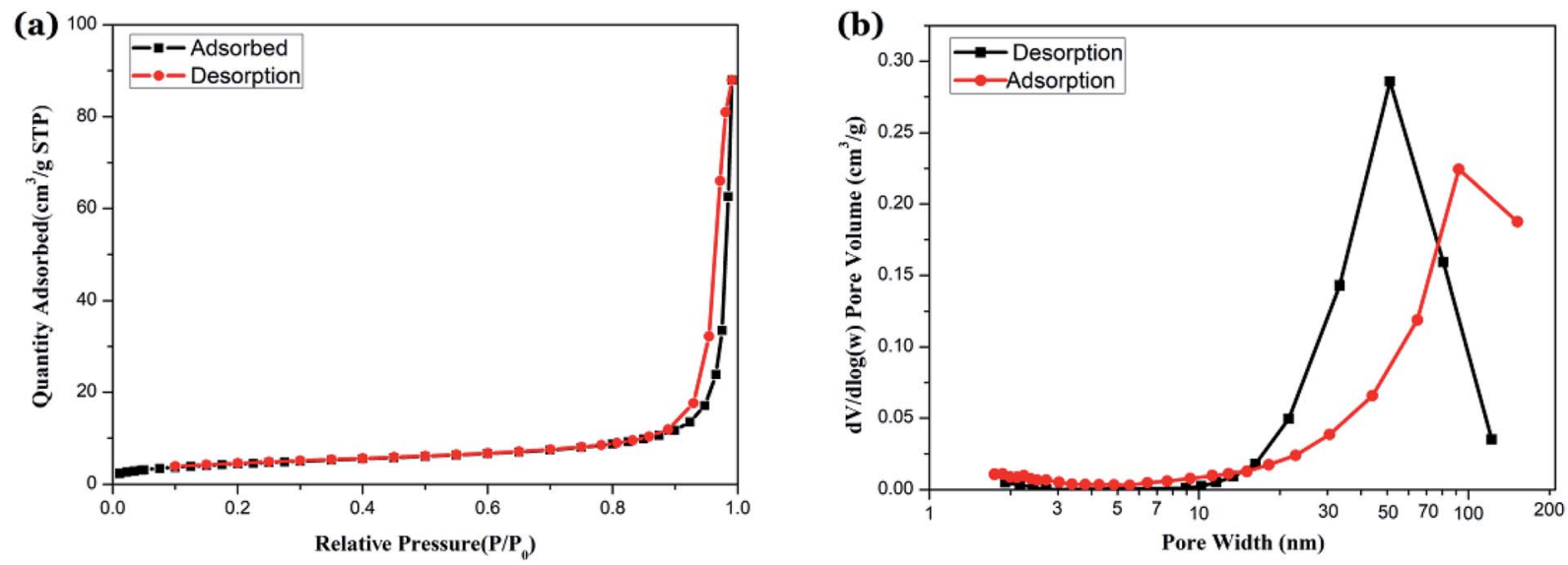

Fig. 8 Isothermal adsorption characteristics and pore size distribution characterization of samples (a) $\mathrm{N}_{2}$ adsorption-desorption isotherm curves of sample; (b) BJH pore size distribution curves of sample. 

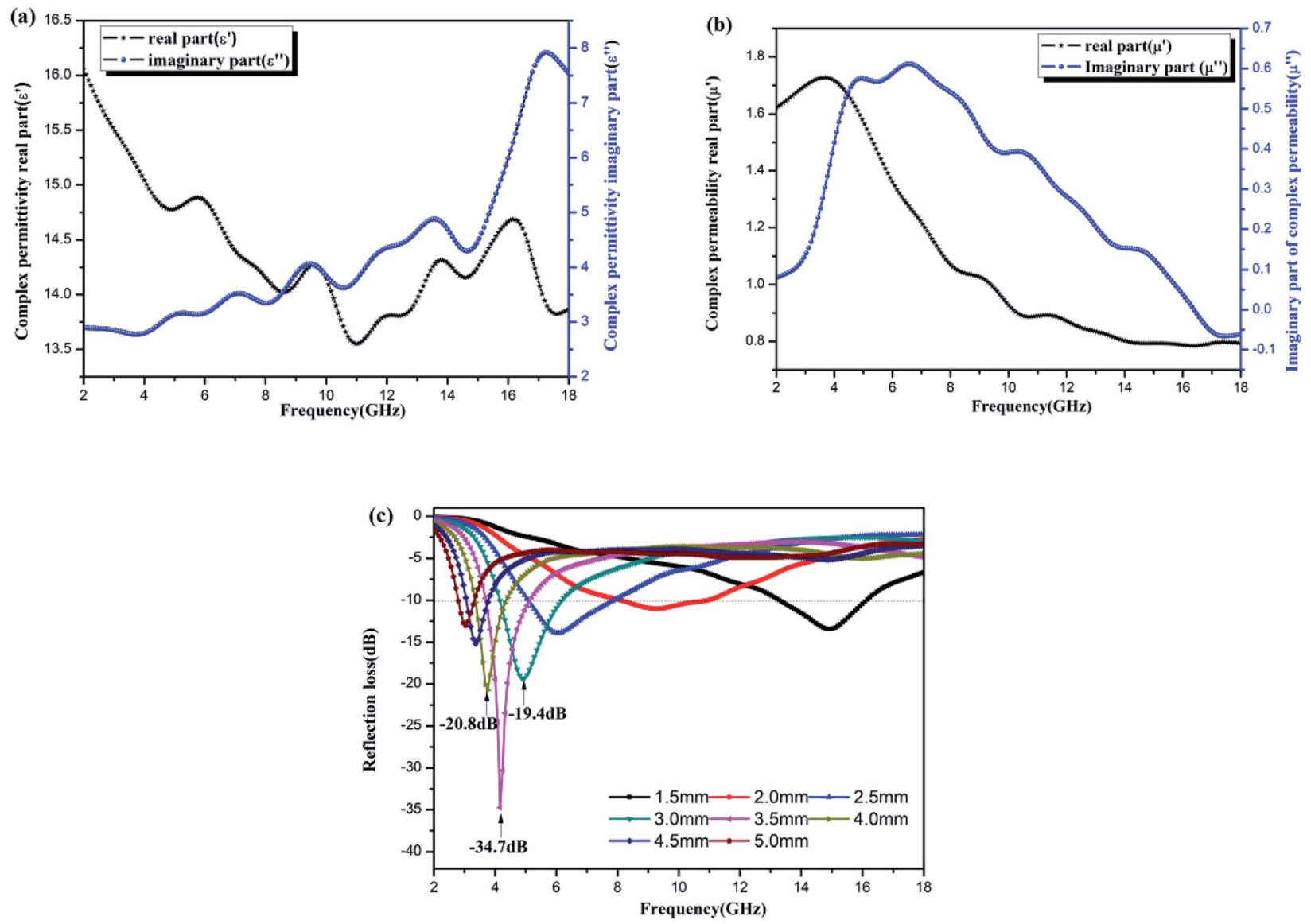

Fig. 10 Electromagnetic parameters and wave absorbing properties of NZFO. (a) The real part $\left(\varepsilon^{\prime}\right)$ and imaginary part $\left(\varepsilon^{\prime \prime}\right) ;(\mathrm{b})$ the real part $\left(\mu^{\prime}\right)$ and imaginary part $\left(\mu^{\prime \prime}\right)$, (c) the reflection loss curve with frequency.

is $\mathrm{Zn}^{2+}>\mathrm{Fe}^{3+}>\mathrm{Ni}^{2+}$, so the cation distribution is $\left(\mathrm{Zn}_{0.45}{ }^{2+} \mathrm{Fe}_{0.5}{ }^{3+}\right)$ $\left[\mathrm{Ni}_{0.55}{ }^{2+} \mathrm{Fe}_{1.5}{ }^{3+}\right] \mathrm{O}_{4}$, forming spinel ferrite. ${ }^{46}$ With the addition of $\mathrm{Zn}^{2+}$, the tendency of metal ions occupying the A site increases, some $\mathrm{Fe}^{3+}$ occupying the A site will enter the $\mathrm{B}$ site. $\mathrm{As}^{\mathrm{Zn}^{2+}}$ is a non-magnetic ion, the magnetic moment of the $\mathrm{A}$ site ion decreases, while the magnetic moment of the $\mathrm{B}$ site ion increases, which makes the magnetic moment of $\mathrm{Ni}_{0.55} \mathrm{Zn}_{0.45^{-}}$ $\mathrm{Fe}_{2} \mathrm{O}_{4}$ increase compared with that of the undoped $\mathrm{Zn}^{2+}$. The increase of magnetic moment can increase the saturation magnetization and further enhance the permeability of the material. However, the large number of holes left by the removal of organic matter during the burning process on one hand enhances the specific surface area of microwave absorption and increases the dielectric absorption capacity, but on the other hand, the hollow structure is not conducive to the formation of large magnetic domains, hindering the transmission of magnetic and making the permeability of the sample slightly less than diatomite/Ni-Zn ferrite.

\section{Conclusion}

$\mathrm{Ni}-\mathrm{Zn}$ ferrioxalate precursors with different particle size ratios were prepared by coprecipitation method with controlled temperatures and time. High-purity $\mathrm{Ni}_{0.55} \mathrm{Zn}_{0.45} \mathrm{Fe}_{2} \mathrm{O}_{4}$ powders with porous cavity structure were prepared by calcining the precursors in oxygen atmosphere at $600-700{ }^{\circ} \mathrm{C}$ for $2 \mathrm{~h}$. The density of NZFO powders with porous chopper-like structure is only $0.76-0.78 \mathrm{~g} \mathrm{~cm}^{-3}$, which is about $1 / 3$ of the density of general $\mathrm{Ni}-\mathrm{Zn}$ ferrite. The microwave absorbing property test shows that the samples have good dielectric properties and low reflectivity up to $-34.7 \mathrm{~dB}$. It is a kind of microwave absorbing agent with low density and good absorbing property, and the test results of TEM, XPS and $\mathrm{N}_{2}$ adsorption-desorption isotherms show that the excellent performance is derived from the presence of a large number of mesopores in the ferrite. In addition, other transition ferrites, including porous nanoscale $\mathrm{CoFe}_{2} \mathrm{O}_{4}, \mathrm{NiFe}_{2} \mathrm{O}_{4}$, and other three-element and multiple metal oxide materials, can also be prepared using this method.

\section{Conflicts of interest}

There are no conflicts to declare.

\section{Acknowledgements}

This work has been funded by the National Natural Science Foundation of China (21361007); 


\section{References}

1 Y. D. Yin, R. M. Rioux, C. K. Erdonmez, et al., Science, 2004, 304, 711-714.

2 D. Wang, Q. Wang and T. Wang, Nanotechnology, 2011, 22, 135604.

3 Z. H. Zhong, D. L. Wang, Y. Cui, et al., Science, 2003, 302, 1377-1379.

4 D. W. Guo and J. J. Feng, Surf. Interfaces, 2017, 9, 9-12.

5 M. M. Kothawale, R. B. Tangsali, G. K. Naik, et al., Am. Inst. Phys., Conf. Proc., 2011, 1447, 317-318.

6 M. Ali, M. Khan, F. Chowdhury, et al., Physics, 2016, 1728, 020506.

7 A. K. Singh, T. C. Goel and R. G. Mendiratta, Phys. Status Solidi, 2004, 201, 1453-1457.

8 M. M. Kothawale, R. B. Tangsali, G. K. Naik, et al., J. Supercond. Novel Magn., 2013, 26, 3293-3298.

9 M. Wang, Preparation and microwave absorption performance of nickel zinc ferrite and its composites, Nanjing University of Aeronautics and Astronautics, China Nanjing, 2015.

10 Q. L. Li, C. B. Chang, H. X. Jing, et al., J. Alloys Compd., 2010, 495, 63-66.

11 E. V. Gopalan, I. A. A. Omari, K. A. Malini, et al., J. Magn. Magn. Mater., 2009, 321, 1092-1099.

12 X. Li, Q. Li, Z. G. Xia, et al., J. Alloys Compd., 2008, 458, 558563.

13 N. Wakiya, K. Muraoka, T. Kadowaki, et al., J. Magn. Magn. Mater., 2007, 310, 2546-2548.

14 V. C. Flores, D. B. Baqués, F. P. Delgado, et al., Phys. Status Solidi, 2010, 204, 1742-1745.

15 S. Bid and S. K. Pradhan, Mater. Chem. Phys., 2004, 84, 291301.

16 M. Šoka, M. Ušáková, R. Dosoudil, et al., AIP Adv., 2018, 8, 047802.

17 X. Chen, Z. Chen and D. Hu, Guangdong Chem. Ind., 2011, 38, 18-19.

18 S. Richa, A. K. Tyagi, D. S. Ahlawat, et al., Int. J. Innov. Res. Sci. Eng., 2016, 2, 501-507.

19 T. Anjaneyulu, A. T. Raghavender, K. V. Kumar, et al., J. Korean Phys. Soc., 2013, 62, 1114-1118.

20 M. Sivakumar, A. Towata, K. Yasui, et al., Curr. Appl. Phys., 2006, 6, 591-593.

21 B. R. Reddy, T. Sivasankar, M. Sivakumar, et al., Ultrason. Sonochem., 2010, 17, 416-426.

22 R. D. K. Misra, A. Kale, R. S. Srivastava, et al., Mater. Sci. Technol., 2003, 19, 826-830.
23 K. H. Wu, T. H. Ting, C. I. Liu, et al., Compos. Sci. Technol., 2008, 68, 132-139.

24 Y. Y. Gu, S. Peng, Z. Qin, et al., J. Magn. Magn. Mater., 2007, 38, 37-39.

25 S. P. Cui, N. Wang, H. X. Guo, et al., J. Chin. Ceram. Soc., 2016, 44, 1509-1514.

26 M. Wang, Z. H. Ai and L. Z. Zhang, J. Phys. Chem. C, 2008, 112, 13163-13170.

27 I. Ali, M. U. Islam, M. S. Awan, et al., J. Supercond. Novel Magn., 2013, 26, 3315-3323.

28 G. C. Zhu, H. L. Zheng, Z. Zhang, et al., Chem. Eng. J., 2011, 178, 50-59.

29 Y. H. Wu, W. Q. Li and X. M. Shen, Organic chemistry, University of Science \& Technology China Press, China Hefei, 2003.

30 W. Chen, H. L. Zheng, J. Zhai, et al., Spectrosc. Spectral Anal., 2016, 36, 1038-1043.

31 P. A. Moussas and A. I. Zouboulis, Water Res., 2009, 43, 35113524.

32 R. K. Selvan, V. Krishnan, C. O. Augustin, et al., J. Mater. Chem., 2008, 20, 429-439.

33 B. S. Randhawa, J. Mater. Chem., 2000, 10, 2847-2852.

34 R. Tursun, Y. C. Su, Q. S. Yu, et al., J. Alloys Compd., 2019, 773, 288-298.

35 T. Yamashita and P. Hayes, Appl. Surf. Sci., 2008, 254, 24412449.

36 G. Zhao, Y. B. Shang, Q. Li, et al., J. Magn. Mater. Devices, 2012, 43, 1-8.

37 M. Jalalian, S. M. Mirkazemi and S. Alamolhoda, Appl. Phys. A, 2016, 122, 835.

38 S. Brunauer, L. S. Deming, W. E. Deming, et al., J. Am. Chem. Soc., 1940, 62(7), 1723-1732.

39 M. Vafaeezadeh, A. Fattahi, et al., RSC Adv., 2014, 4, 1664716654.

40 J. P. Gao, X. Y. Liu, X. W. Lu, et al., Chin. J. Inorg. Chem., 2012, 28, 1200-1204.

41 Y. Q. Qu, H. B. Yang, N. Yang, et al., Mater. Lett., 2006, 60, 3550-3552.

42 F. L. Michel, X-Ray Spectrom., 1988, 17, 103-106.

43 C. D. Maria, W. Alejandra, P. Daniel, et al., J. Braz. Chem. Soc., 2009, 20, 445-450.

44 G. B. Sun, B. X. Dong, M. H. Cao, et al., Chem. Mater., 2011, 23, 1587-1593.

45 B. Zhao, G. Shao, B. B. Fan, et al., RSC Adv., 2015, 5, 98069814.

46 S. X. Liu, H. B. Wang, J. C. Huo, et al., China Powder Sci. Technol., 2010, 16, 39-42. 